\title{
Monitoring Atlantic overturning circulation and transport variability with GRACE-type ocean bottom pressure observations - a sensitivity study
}

\author{
K. Bentel, F. W. Landerer, and C. Boening \\ Jet Propulsion Laboratory, California Institute of Technology, 4800 Oak Grove Dr, Pasadena, CA 91109, USA \\ Correspondence to: K. Bentel (katrin.i.bentel@jpl.nasa.gov)
}

Received: 1 July 2015 - Published in Ocean Sci. Discuss.: 14 August 2015

Revised: 20 November 2015 - Accepted: 23 November 2015 - Published: 11 December 2015

\begin{abstract}
The Atlantic Meridional Overturning Circulation (AMOC) is a key mechanism for large-scale northward heat transport and thus plays an important role for global climate. Relatively warm water is transported northward in the upper layers of the North Atlantic Ocean and, after cooling at subpolar latitudes, sinks down and is transported back south in the deeper limb of the AMOC. The utility of in situ ocean bottom pressure (OBP) observations to infer AMOC changes at single latitudes has been characterized in the recent literature using output from ocean models. We extend the analysis and examine the utility of space-based observations of timevariable gravity and the inversion for ocean bottom pressure to monitor AMOC changes and variability between 20 and $60^{\circ} \mathrm{N}$. Consistent with previous results, we find a strong correlation between the AMOC signal and OBP variations, mainly along the western slope of the Atlantic Basin. We then use synthetic OBP data - smoothed and filtered to resemble the resolution of the GRACE (Gravity Recovery and Climate Experiment) gravity mission, but without errors - and reconstruct geostrophic AMOC transport. Due to the coarse resolution of GRACE-like OBP fields, we find that leakage of signal across the step slopes of the ocean basin is a significant challenge at certain latitudes. Transport signal rms is of a similar order of magnitude as error rms for the reconstructed time series. However, the interannual AMOC anomaly time series can be recovered from 20 years of monthly GRACElike OBP fields with errors less than 1 sverdrup in many locations.
\end{abstract}

\section{Introduction}

Changes of the Atlantic Meridional Overturning Circulation (AMOC) and associated poleward ocean heat transport from the equatorial regions influence climate at higher latitudes significantly. It has potentially significant impacts in particular for the Northern Hemisphere as well as northwestern Europe's climate (Manabe and Stouffer, 1999; Srokosz et al., 2012; IPCC, 2014). The dynamics of the mean and time-variable North Atlantic MOC have been described in several recent studies, using observations from hydrographic arrays such as RAPID-MOCHA (MOCHA - Meridional Overturning Circulation and Heatflux Array; e.g., Kanzow et al., 2010; Elipot et al., 2013) and MOVE (Meridional Overturning Variability Experiment; Send et al., 2011), as well as model studies (e.g., Vellinga and Wood, 2002; Bingham and Hughes, 2008, 2009a; McCarthy et al., 2012; Wunsch and Heimbach, 2013).

AMOC variability manifests itself in ocean bottom pressure (OBP) changes, in particular along the western boundary (e.g., Roussenov et al., 2008; Bingham and Hughes, 2008, 2012), but also in sea surface height changes (e.g., Bingham and Hughes, 2009b; Willis, 2010; Frajka-Williams, 2015) and in sea surface temperatures (Knight et al., 2005; Zhang, 2008). The viability of using OBP along the eastern and western boundaries to calculate the basin-wide meridional geostrophic transports was first demonstrated with numerical ocean simulations (e.g., Bingham and Hughes, 2008, 2009a). More recently, Elipot et al. (2013) used bottom pressure recorder (BPR) measurements along the western boundary to monitor the AMOC. However, due to the inherent drift problems of in situ BPRs, their analysis was limited to 
timescales shorter than 1 year, as well as to the specific latitude of instrument deployment.

In the present study, we build upon previous results (Roussenov et al., 2008; Bingham and Hughes, 2008, 2009a) and examine the feasibility of using OBP to derive AMOC variations. While the previous works examined the relationships between OBP and AMOC variability in the North Atlantic at specific latitudes (e.g., 40, 48 and $50^{\circ} \mathrm{N}$ ), we examine the entire latitude and depth range from 20 through $60^{\circ} \mathrm{N}$. Thereby, we specifically investigate the detectability of AMOC variability using OBP inferred from time-variable gravity observations such as those provided by the GRACE (Gravity Recovery and Climate Experiment) satellites (Tapley et al., 2004). The GRACE gravity observations provide complete global spatial coverage and monthly time series of ocean mass changes from 2002 until present. The challenge in using GRACE OBP to derive AMOC variability is the relatively coarse spatial resolution as well as overall signal-tonoise levels. To estimate the effects of limited spatial resolution, we use data from the Estimating the Circulation and Climate of the Ocean, Phase II (ECCO2) ocean state estimate and convert the synthetic OBP fields to a GRACElike resolution. To also capture signal contamination from nearby land hydrology variations (which are also recorded by GRACE), we evaluate the effects of terrestrial land water storage on GRACE-like OBP retrievals by combining the ocean state estimate with a land hydrology model. Our results indicate that, even though resolution along the steep basin slopes is challenging in GRACE-like OBP fields, the recovery of the meridional volume transports with errors less than $\pm 1 \mathrm{~Sv}$ is possible for specific regions and timescales.

Our paper is organized as follows: in Sect. 2, we briefly review the pertinent aspects of the underlying theories and relationships between OBP and AMOC transports; then we describe the ocean state estimate ECCO2 and discuss the AMOC and OBP signals in the model at GRACE-like spatial resolution, including signal contamination effects from land hydrology; in Sect. 3 we present results for deriving AMOC from the model data directly compared to results for AMOC from data smoothed to a GRACE-like resolution.

\section{Methods and data}

\subsection{Theoretical background}

The Atlantic Meridional Overturning Circulation consists of a northward flow in the upper layer of the ocean (mostly between the surface and $1000 \mathrm{~m}$ depth; Srokosz et al., 2012; Wunsch and Heimbach, 2013) and a return flow to the south in the deeper layer of the ocean (between approximately 1000 and $5000 \mathrm{~m}$ depth). The meridional stream function $\psi(y, x)$ is derived from meridional velocities $\left(v_{y}\right)$ by integration over longitudes $(x)$ and from the surface $(\eta)$ to depth (z) (Marotzke et al., 1999):

$\psi(y, z)=\int_{W}^{E} \int_{z}^{\eta} v_{y} \mathrm{~d} z \mathrm{~d} x$.

As the large-scale flows are dominated by a geostrophic balance, the meridional transport per unit depth $T(z)$, at a particular latitude $(y)$ and depth $(z)$, can be derived from the zonal bottom pressure differences $p_{\mathrm{E}}$ and $p_{\mathrm{W}}$ at the eastern and western basin boundaries by taking

$T(z)=\frac{p_{\mathrm{E}}(z)-p_{\mathrm{W}}(z)}{\rho_{0} f}$,

where the constants are the Coriolis parameter $f$ and the mean sea water density $\rho_{0}$ (Marotzke et al., 1999; Roussenov et al., 2008). Acceleration and stress terms are neglected, as they only play a role in the Ekman layer and in the deep bottom layers. For a more rigorous derivation and justification for Eq. (2) we defer to Bingham and Hughes (2008, 2009a) and Roussenov et al. (2008), and references therein. Using the geostrophic approximation, the depth-integrated meridional transports $T(z)$ at a particular latitude $(y)$ can then be used to give the meridional stream function $\psi$ at that latitude:

$\psi(y, \Delta z)=\frac{1}{\rho_{0} f} \int_{z_{1}}^{z_{2}}\left(p_{\mathrm{E}}-p_{\mathrm{W}}\right) \mathrm{d} z$.

Equation (3) provides a method to derive the geostrophic component of the AMOC stream function (or volume transport between two layers) from ocean bottom pressure data along the boundaries of the ocean basin. Possibly intervening topography (i.e., mid-ocean ridges) should in theory be considered when evaluating Eq. (3), but Bingham and Hughes $(2008,2009 a)$ demonstrated in an ocean model that, for interannual time-variable transports in the North Atlantic, bottom pressure variability is concentrated along the western boundary, and it is sufficient to use only the outermost eastern and western points across the basin section (if a basin-mean or depth-averaged boundary pressure is removed from $p_{\mathrm{W}}$ in Eq. (3), it is also possible to use only bottom pressure on the western boundary (Bingham and Hughes, 2009a). Furthermore, the dominance of the western boundary variations was recently confirmed from hydrographic in situ data (Elipot et al., 2014). We reconfirmed this with the ocean model ECCO2 (see below for details), and we thus use $p_{\mathrm{E}}$ and $p_{\mathrm{W}}$ only for our analyses in the North Atlantic. While knowledge of $p_{\mathrm{E}}$ and $p_{\mathrm{W}}$ along the boundaries is in principle sufficient to infer $\psi(y, z)$, the actual measurement of these terms is challenging. In situ BPRs suffer from notorious drift problems and thus require drift corrections that usually inhibit any inferences about longer-than-annual variations (Polster et al., 2009). An alternative measurement of OBP variations can be obtained from time-variable gravity observations from 


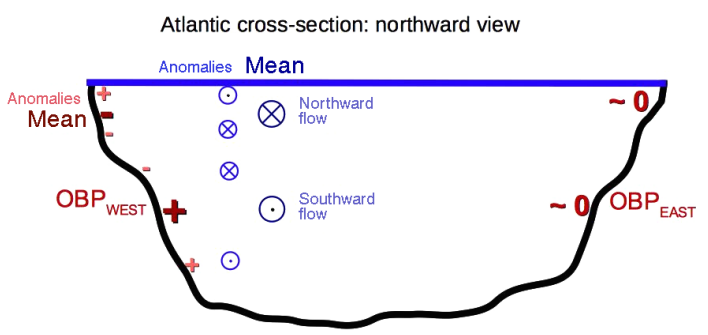

Figure 1. Cross section of the North Atlantic with an illustration of north- and southward flow temporal mean and anomalies (blue) and associated ocean bottom pressure mean and anomalies (red) along the basin boundaries. Note that in the actual ocean the bottom pressure signals are largest along the western boundary, and the bottom pressure at the eastern boundary is very small and can be neglected. Ocean bottom pressure anomalies are observable with satellite gravimetry.

space as currently acquired by the GRACE satellites. The main challenge for OBP inferred from time-variable gravity is the limited horizontal resolution, as well as the required signal sensitivity. Due to the altitude (about $450 \mathrm{~km}$ ) and orbit configuration of the two GRACE satellites, the horizontal spatial resolution is limited to approximately $300 \mathrm{~km}$ (e.g., Chambers and Bonin, 2012; Landerer and Swenson, 2012). Much of the AMOC-related OBP signals occur along the narrow and steep western boundary slope and are thus difficult to resolve (which is also a limitation to in situ pressure observations). In Sect. 3, we therefore quantify these resolution issues using synthetic data at GRACE-like spatial resolutions to quantify the feasibility of the OBP AMOC approach. Also note that GRACE can only resolve OBP variations relative to a (arbitrary) time mean. Therefore, all terms in Eqs. (1)(3) are taken to be anomalies and only AMOC variations can be inferred, but not its long-term average. The mean flow in the North Atlantic and the resulting OBP anomalies are illustrated in Fig. 1.

\subsection{Synthetic OBP observations}

We use the ECCO2 (Menemenlis et al., 2008) to reconstruct the AMOC variability from simulated OBP observations in the North Atlantic as in Eq. (3). ECCO2 is an ocean state estimate which optimally fits ocean observations using a Green's function approach. The OBP-derived AMOC reconstructions are compared against the model baseline AMOC, which represents the model truth and is based on the meridional velocities according to Eq. (1). Similar to Bingham and Hughes (2008), we extract zonal OBP profiles following the model's bathymetry and then interpolate these values to regularly spaced $100 \mathrm{~m}$ depth intervals. Monthly ECCO2 OBP data at a horizontal resolution of $0.25^{\circ}$ are computed for the time period January 1993 through December 2012, for the area of the North Atlantic, 80 to $0^{\circ} \mathrm{W}$ and 20 to $60^{\circ} \mathrm{N}$. We remove a global mean OBP term to enforce mass conservation (Great-

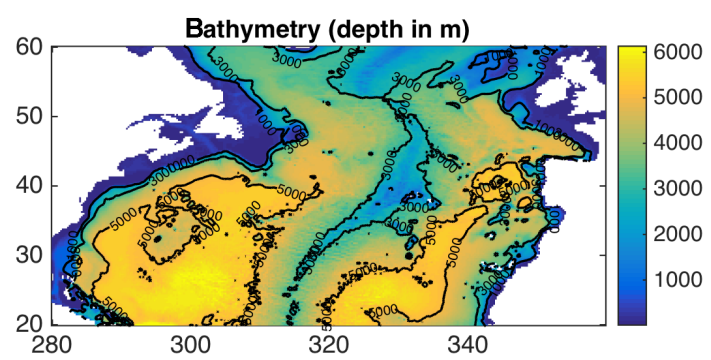

Figure 2. Bathymetry for the North Atlantic with the 1000, 3000, and $5000 \mathrm{~m}$ depth contour lines.

batch, 1994). For the subsequent analysis, we remove a trend and the mean annual climatology signal from all time series (OBP, velocities), and we smooth with a 15 -month running mean to focus on interannual signals only.

\subsection{GRACE-like OBP fields: mascons and spherical harmonics}

Conventional GRACE gravity field solutions are given in global spherical harmonic basis functions without any type of constraints (e.g., Chambers and Bonin, 2012). In contrast, the GRACE mascon solutions employ geophysical constraints and provide an improved spatial localization. A best-fitting gravity value is estimated for each mascon cell (here: $3^{\circ} \times 3^{\circ}$ equal-area cells). Importantly, the mascon solution makes the application of empirical post-processing filters (i.e., destriping) unnecessary and thus features a better signal-to-noise ratio at smaller spatial scales. We evaluate OBP output from the $\mathrm{ECCO} 2$ ocean state estimate as provided at a $0.25^{\circ}$ degree resolution. To create GRACE-like synthetic observations that match actual GRACE resolution, we bin-average the OBP fields to a $3^{\circ}$ equal-area grid. This grid is identical to the JPL mascon RL05M grid (Watkins et al., 2015). Second, the OBP data are smoothed to resemble the resolution of the standard GRACE solutions, which are represented in spherical harmonics truncated at degree and order 60 , and smoothed with a Gaussian filter with $300 \mathrm{~km}$ radius. This would be necessary for real GRACE data in order to reduce noise and correlated errors. This processing provides approximately the resolution that is currently achieved with the GRACE satellites. However, we do not consider instrument and resulting measurement errors in the gravity field retrieval from GRACE measurements in order to focus on the issues of spatial resolution and signal leakage. The spatial smoothing and averaging of the $0.25^{\circ} \mathrm{OBP}$ fields lead to significant resolution reduction in particular in highly energetic regions like the Gulf Stream, as well as in regions of steep bathymetry (Figs. 2 and 3). Additional post-processing filters employed to reduce correlated errors in GRACE would further dampen geophysical signals (e.g., Landerer and Swenson, 2012). 

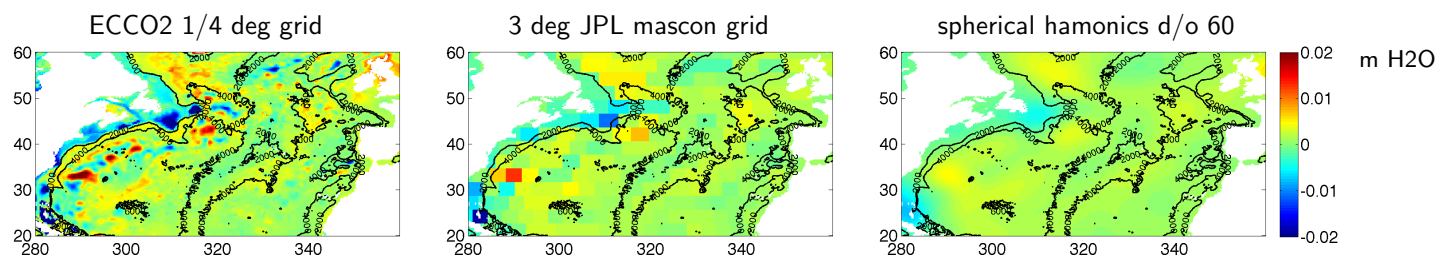

Figure 3. OBP snapshots for January 2012 for the different simulated OBP observation time series: left: $0.25^{\circ}$ ECCO2 resolution; center: GRACE JPL mascon resolution (ca. $3^{\circ}$ ); right: GRACE spherical harmonic resolution to spherical harmonic degree 60, smoothed with a $300 \mathrm{~km}$ Gaussian filter.
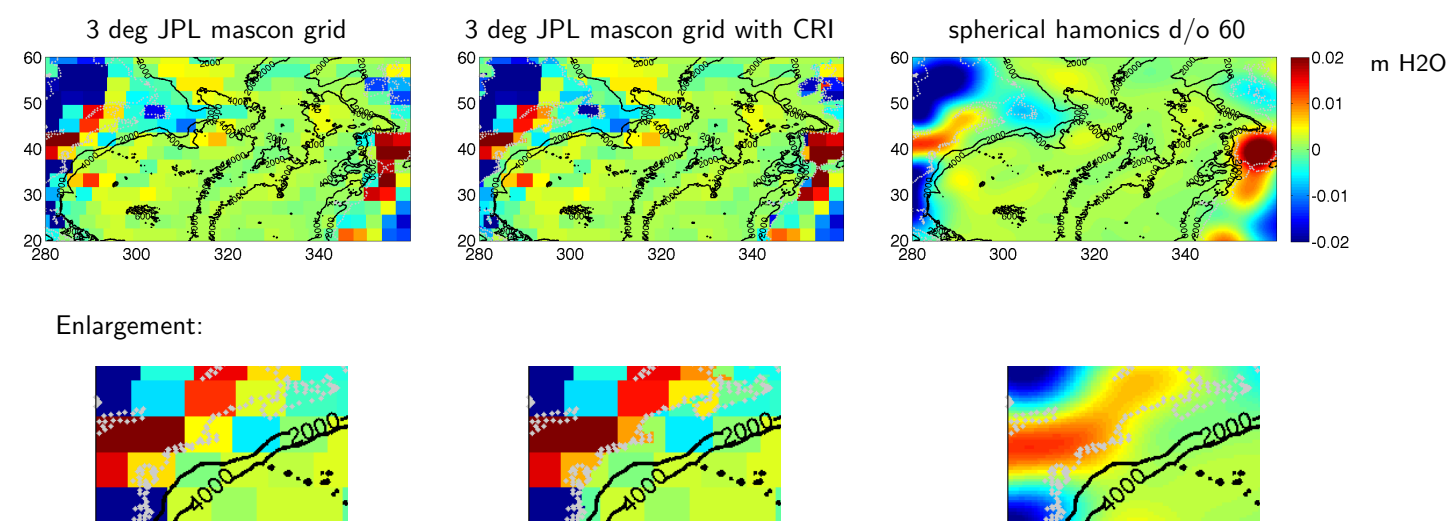

Figure 4. OBP snapshots for January 2012 for the simulated observations, including the continental hydrology signal: left: JPL mascon grid without CRI (coastline resolution improvement); center: JPL mascon grid with CRI; right: spherical harmonics to degree 60. Since the ECCO2 original data are not smoothed, the OBP pixels do not get affected by nearby land hydrology signals (therefore no additional plot for hydrology). Second row shows enlargements of the two mascon-resolution data sets including hydrology and details for CRI.

\subsection{Leakage effects}

\subsubsection{From continental hydrology}

In order to make the synthetic OBP observations more realistic, we add a continental hydrology signal that we obtain from the Global Land Data Assimilation System (GLDAS) Noah hydrology model (Rodell et al., 2004). The continental hydrology signal does not affect the OBP data on the $0.25^{\circ} \mathrm{ECCO} 2$ grid. However, when the data are smoothed, the hydrology signal "leaks" into the OBP data (Wahr et al., 1998; Chambers and Bonin, 2012), causing contamination of ocean grid points by land hydrology variations (Fig. 4). As the following analysis will show, the effects of land signal leakage tend to dominate the error budget in the meridional transport and overturning calculations, in particular for the near-coastal shallower shelf areas (above ca. $1000 \mathrm{~m}$ ). Therefore, a leakage correction (e.g., CRI (coastline resolution improvement) filter for the mascon grid) is essential in order to employ GRACE OBP observations: mascons that cover both land and ocean area still obtain only one value to represent the mass change within that mascon. To better distinguish where the signals originate from, a so-called CRI filter is employed (see Watkins et al. (2015) for details). Essentially, the CRI process separates land hydrology and ocean signals based on a priori co-variance information from both land and ocean forward simulations. This CRI filter reduces the leakage of the continental hydrology signal into the adjacent ocean mascons significantly (Fig. 4). Spherical harmonic GRACE solutions can be corrected for leakage as well, using an iterative approach. However, due to large smoothing filters which need to be applied ( $300 \mathrm{~km}$ Gaussian smoothing radius) and errors in the hydrology models, these corrections may not be sufficient enough to reduce overall noise and errors in the solutions for our purposes. We therefore do not consider leakage correction for spherical harmonics further here.

\subsubsection{Due to steep bathymetry gradients}

Besides signal leakage from continental hydrology, leakage of the signal within the ocean between different depths must be considered. Especially along the steep basin boundary slopes, there are instances where one $3^{\circ}$ mascon covers a number of different depth layers. Thus, the different OBP in these layers cannot be resolved. One possibility to make this leakage effect smaller is optimal placement in longitude of the individual mascon cells. In the JPL mascon grid, it is possible to shift the mascons in longitude direction (for each mascon latitude) without influencing mascons in other lati- 
Table 1. Overview of the different resolutions of the synthetic OBP data.

\begin{tabular}{|c|c|c|}
\hline Acronym & Characteristics & Spatial resolution \\
\hline$T^{\mathrm{O}}$ & Original ECCO2 OBP grid & $0.25^{\circ}$ \\
\hline$T^{\mathrm{SH} 60}$ & $\begin{array}{l}\text { Spherical harmonic expansion up to } d / o 60 \text {, smoothed with a Gaussian } \\
\text { filter of } 300 \mathrm{~km} \text { radius and synthesized back to a point grid }\end{array}$ & $3^{\circ}$ \\
\hline$T^{\mathrm{MSC}}$ & $\begin{array}{l}\text { Interpolated to ca. } 3^{\circ} \text { equal-area JPL mascon grid, which is described } \\
\text { in Watkins et al. (2015) }\end{array}$ & $3^{\circ}$ \\
\hline$T^{\mathrm{MSC}+\mathrm{CRI}}$ & $\begin{array}{l}\text { Interpolated to ca. } 3^{\circ} \text { equal-area JPL mascon grid, and CRI (coastline } \\
\text { resolution improvement) applied (Watkins et al., 2015) }\end{array}$ & $3^{\circ}$ \\
\hline$T^{\mathrm{MSC}+\mathrm{POSOPT}}$ & $\begin{array}{l}\text { Interpolated to a grid similar to the JPL mascon grid, with the grid cells' } \\
\text { longitude position adjusted to minimize rms error (minimizing leakage } \\
\text { over different depths and land hydrology leakage simultaneously) }\end{array}$ & $3^{\circ}$ \\
\hline
\end{tabular}

tudes. We create a synthetic data set where we position the JPL mascons optimally in order to resolve as much of the western and eastern boundary signal as possible.

\section{Results}

Equation (3) is evaluated for different synthetic OBP resolutions derived from $\mathrm{ECCO} 2$ in the North Atlantic: the original ECCO2 $0.25^{\circ}$ grid $\left(T^{\mathrm{O}}\right)$, a GRACE spherical harmonics grid truncated at degree and order $60\left(T^{\mathrm{SH} 60}\right)$, GRACE mascon grids, without $\left(T^{\mathrm{MSC}}\right)$ and with $\left(T^{\mathrm{MSC}+\mathrm{CRI}}\right) \mathrm{CRI}$ filter, and position-optimized mascons $\left(T^{\mathrm{MSC}+\mathrm{POSOPT}}\right)$. See Table 1 for a summary of the corresponding OBP grid characteristics. The OBP-reconstructed transports are then evaluated against the model baseline transports, which are derived directly from the meridional velocities. While the OBP signal on the western basin boundary contains most of the AMOC information, a basin mode has to be taken into account, either by differencing with the signal on the eastern boundary or by removing a depth-averaged OBP to remove variations not contributing to geostrophic transports (Bingham and Hughes, 2008, 2009a). Even though the eastern boundary OBP contributes only a small fraction to the AMOC signal, we take the signal on the eastern boundary into account rather than removing a depth mean. By removing a mean over all depths, leakage signal from continental hydrology would contaminate the OBP data at greater depths as well as the shallower areas, and degrade the AMOC transport estimates compared to the east-west difference. Thus, we consider the eastern boundary in our calculation, even though the data on the eastern boundary reduce the signal-to-noise ratio.

\subsection{Meridional transports from OBP integration}

For each of the synthetic OBP data sets, meridional transport time series are computed in $1^{\circ}$ latitude increments and over $100 \mathrm{~m}$ depth intervals, and the rms differences between reconstructed and model reference time series are computed for each depth and latitude (Fig. 5). The results for OBP without a hydrology signal (Fig. 5, top row) at the $0.25^{\circ}$ native
ECCO2 resolution lead to errors smaller than $0.5 \mathrm{~Sv} \mathrm{~km}^{-1}$ for depths between 1000 and $5000 \mathrm{~m}$. At latitudes lower than $50^{\circ} \mathrm{N}$, errors above 1000 and below $5000 \mathrm{~m}$ vary with latitude and depend on the bathymetry gradients. At GRACElike resolutions (panels $b$ and $c$ in Fig. 5), the errors are slightly higher across all depths, and at specific latitudes, e.g., at $25-30^{\circ} \mathrm{N}$, there are significant signal leakage errors that introduce significant transport retrieval errors. The steep topography (Fig. 2) at these latitudes causes one $3^{\circ}$ mascon to cover depth layers from above $1000 \mathrm{~m}$ to below $3000 \mathrm{~m}$. Very high errors $\left(>1.5 \mathrm{~Sv} \mathrm{~km}^{-1}\right)$ occur in the upper $100 \mathrm{~m}$ depth for all latitudes due to the non-geostrophic, wind-driven transport in the Ekman layer, which cannot be recovered from east-west OBP difference observations. In all following computations of the geostrophic volume transports, we therefore exclude the upper $100 \mathrm{~m}$ (in the OBPderived as well as in the reference transport time series).

While the GLDAS hydrology signal does not affect the results on the ECCO2 model grid (Fig. 5, panel d), significant leakage errors from land hydrology are introduced when the OBP and hydrology signals are spatially smoothed to GRACE-like resolutions (Fig. 5e and f). Without hydrology leakage, errors of $1.5 \mathrm{~Sv} \mathrm{~km}^{-1}$ and larger only occur in the uppermost $100 \mathrm{~m}$ when Ekman transports are not accounted for, and at $25^{\circ} \mathrm{N}$ for the mascons. With hydrology leakage effects, the GRACE-like OBP resolutions lead to high errors that extend into deeper layers, down to 3000 to $5000 \mathrm{~m}$ depth for latitudes 32 to $40^{\circ} \mathrm{N}$. This effect is highly latitudedependent, since the lower resolution only degrades the results if smoothing occurs over too many depth layers and/or the coastline. In this way, the results are very dependent on the bathymetry and the proximity of depth contours to land points, as well as signal amplitudes over land. In addition, pressure variations over steep bathymetry cannot be adequately resolved in the spatially smoothed data. For the mascon resolution, the leakage effect changes with mascon latitudes. Significant hydrology signal leakage occurs especially between 35 and $40^{\circ} \mathrm{N}$, down to a depth of $2000 \mathrm{~m}$. For spherical harmonics, the leakage effects are more smeared out over 

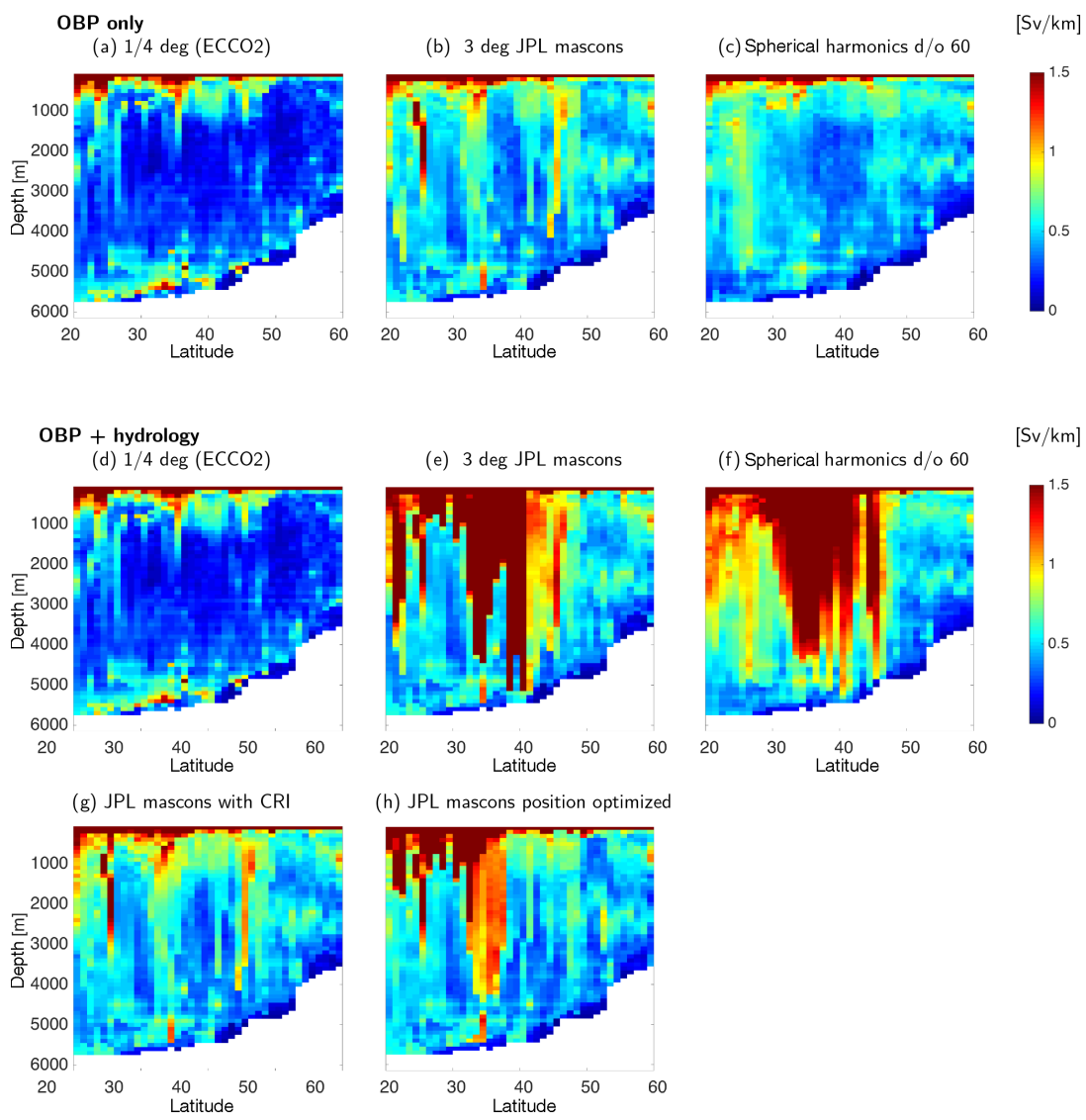

(h) JPL mascons position optimized

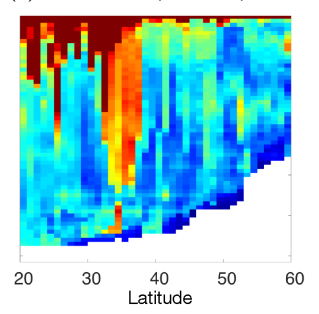

Figure 5. Root mean square errors for the computed transport per unit depth $T$ in $\mathrm{Sv} \mathrm{km}^{-1}$ from eastern and western boundary OBP according to Eq. (3). OBP only (top row) and OBP + hydrology (second and third row) for each of the synthetic observation time series. Significant leakage errors are introduced with the GRACE-like resolutions (second row); CRI filtering of the mascons and optimizing their position in longitude can remove a major part of the leakage errors.

depths and latitudes. Between 20 and $40^{\circ} \mathrm{N}$ down to $3000 \mathrm{~m}$ depth, errors are between 1 and $2 \mathrm{~Sv} \mathrm{~km}^{-1}$. For the mascon results, the CRI filter reduces much of the leakage artifacts; the major leakage effect between 35 and $40^{\circ} \mathrm{N}$ is reduced from errors exceeding $2 \mathrm{~Sv} \mathrm{~km}^{-1}$ to less than $1 \mathrm{~Sv} \mathrm{~km}^{-1}$ by $2000 \mathrm{~m}$ depth.

Another strategy to reduce leakage is to optimize the placement of the individual mascons in longitude direction (for each mascon latitude). When mascon boundaries align with the coastline, hydrology leakage is reduced; when an individual mascon does not cover too many depth layers, leakage between depths in the ocean is reduced. The optimal mascon position (in longitude) is found by minimizing both types of errors simultaneously. While there are latitudes where land leakage is not reduced as much by optimal positioning as by the CRI filter (e.g., $22,33^{\circ} \mathrm{N}$ ), errors in the deeper layers between 2000 and $3000 \mathrm{~m}$ depths are smaller than for the CRI results. For 30 to $50^{\circ} \mathrm{N}$ and between 1500 and $5000 \mathrm{~m}$ depth most errors are below $0.5 \mathrm{~Sv} \mathrm{~km}^{-1}$ with the position-optimized mascons, while they tend to be between 0.5 and $1 \mathrm{~Sv} \mathrm{~km}^{-1}$ in the results with CRI. Note that
CRI only treats and reduces land leakage; it does not mitigate leakage between different ocean depths layers (Watkins et al., 2015).

\subsection{Reconstructing north- and southward transports}

The maximum of the mean model AMOC in ECCO2 lies at $32^{\circ} \mathrm{N}$ and $909 \mathrm{~m}$ depth (Fig. 6). Thus, net transports from the surface to about $909 \mathrm{~m}$ are northward, and net transports below about $909 \mathrm{~m}$ to a depth of about $5000 \mathrm{~m}$ are southward. However, the depth of maximum overturning varies with latitude and in time. The circulation below about $5000 \mathrm{~m}$ is linked to the Atlantic Bottom Water and is not considered in the following. As mentioned before, the uppermost $100 \mathrm{~m}$ of the ocean is also excluded, because the Ekman circulation and related transports cannot be recovered from OBP gradients. Over interannual periods, the net water volume transported northward should equal the water volume transported back south (e.g., Srokosz et al. (2012) or Kanzow et al. (2007) for 10-day timescales). Thus, it should be sufficient to observe either the northward or the southward transport in order to reconstruct the interannual AMOC transport varia- 

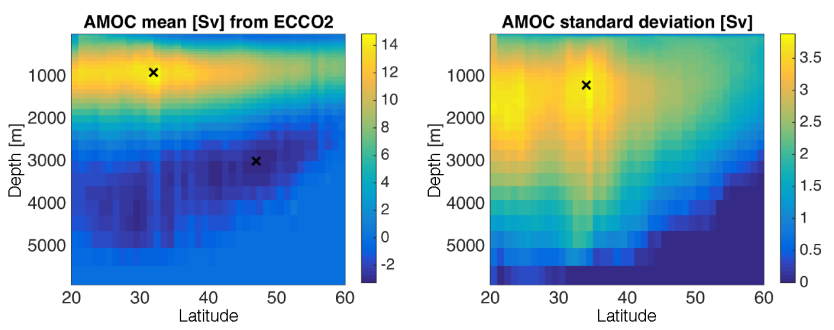

Figure 6. Left panel: time mean of AMOC from ECCO2, with maximum at $32^{\circ} \mathrm{N}, 909 \mathrm{~m}$ depth, minimum at $47^{\circ} \mathrm{N}, 2990 \mathrm{~m}$ depth, both indicated by marker X. Right panel: variability of AMOC from ECCO2, maximum at $34^{\circ} \mathrm{N}, 1200 \mathrm{~m}$ depth, indicated by marker $\mathrm{X}$.

tions, as long as the depth of maximum overturning circulation is known. Since we do not know the correct depth of maximum overturning for each latitude and time, we make an assumption of a constant depth, which introduces only a small error.

In what follows, three different depth layers are considered in more detail: 100 to 909,909 to 3000 , and 3000 to $5000 \mathrm{~m}$ depth; detectability of the AMOC signal in each of these three layers from GRACE-like OBP resolutions is assessed. The first layer covers the northward transport (down to the maximum of the mean AMOC, Fig. 6); the second layer covers steep ocean basin slopes for most latitudes (Fig. 2); and the third layer covers deeper transport, where the bathymetry is less steep (Fig. 2) and therefore can be expected to be more favorable for GRACE-like resolutions.

Figure 7 shows rms errors and correlation coefficients for the reconstructed transport versus the model baseline for the three layers. The center plot is a selection of the plots on the left, with an adjusted axis to enhance details for the solutions with smaller errors (ECCO2 native resolution and mascons with CRI). The reconstructed transport from OBP at the $\mathrm{ECCO} 2$ native $0.25^{\circ}$ resolution (black curves Fig. 7) matches the model baseline transport best; it shows smallest rms errors (about $0.5 \mathrm{~Sv}$ and below, with a maximum of $1 \mathrm{~Sv}$ ) for all the three layers and the highest correlation coefficients. The average rms error and correlation level are similar for all the three layers under consideration. However, when smoothing to GRACE-like resolutions, rms differences become larger and correlation coefficients smaller, due to the much coarser resolution of $3^{\circ}$. For these resolutions, overall and maximum rms errors (Fig. 7, left) are larger for the medium depth layer (909 to $3000 \mathrm{~m}$ ) than for the upper and the deep layers. The larger errors between 20 and $45^{\circ} \mathrm{N}$ in the medium layer for data at GRACE-like resolutions are caused by the steep slopes between about 1000 and $3000 \mathrm{~m}$ depth (Figs. 2 and 4). When the data are smoothed, the OBP values cannot be attributed to the correct depth as the depth interval for one $3^{\circ}$ smoothing interval becomes very large. Between 45 and $60^{\circ} \mathrm{N}$, the depth gradient for a $3^{\circ}$ longitude interval becomes much smaller; i.e., more than one $3^{\circ}$ pixel is needed to cover the depth gradient from 909 to $3000 \mathrm{~m}$.
Thus, OBP at individual depth layers can be better resolved and the transport reconstruction is more accurate, leading to smaller rms error. For the upper transport, rms errors are high ( 0.5 to $2 \mathrm{~Sv}$ ) for spherical harmonics and mascons, and especially high between 30 and $40^{\circ} \mathrm{N}$. These errors are attributed to leakage effects from land hydrology signals (Fig. 5). In the upper layer, the coastline resolution improvement correction makes a big difference: for mascons with CRI (red curve in Fig. 7) the rms errors are at a level similar to the ECCO2 native $0.25^{\circ}$ resolution and below $1 \mathrm{~Sv}$. In the deep layer (3000 to $5000 \mathrm{~m}$ depth), there are still high rms errors of about $3 \mathrm{~Sv}$ between 30 and $40^{\circ} \mathrm{N}$ for spherical harmonics (black dashed curve), because land hydrology leakage extends to depths below $3000 \mathrm{~m}$ for these latitudes (Fig. 5). The CRI algorithm and position optimizing of mascons corrects for these errors; therefore, rms errors for mascons with CRI and position-optimized mascons (red and blue curves) are about and below $1 \mathrm{~Sv}$ in the deep layer for 20 to $45^{\circ} \mathrm{N}$. Beyond $45^{\circ} \mathrm{N}$, the GRACE resolution is well capable of capturing all the OBP signal, since the bathymetry is less steep. Therefore, rms errors decrease and drop below $0.5 \mathrm{~Sv}$ for 50 to $60^{\circ} \mathrm{N}$. In order to show more detail with respect to the signal rms, the two solutions with smaller rms error, i.e., the original ECCO2 grid and mascons with CRI, are plotted again in the center of Fig. 7. Even for these better-performing solutions, the signal rms is of the same order of magnitude as the rms error, with the rms error from the mascon solutions exceeding the signal rms by far in the intermediate layer. The rms errors for the original ECCO2 resolution are mostly just below the signal rms. Even though rms errors for mascons are higher, the results in the upper and deeper layers achieve smaller rms error than signal rms for selected latitudes. As mentioned before, the overturning transport signal is on the edge of detectability in GRACE gravity data, but we show in this study that it is possible with CRI improved mascons for selected latitudes.

Correlation coefficients vary a lot with latitude. While correlation coefficients are highest for the $0.25^{\circ} \mathrm{ECCO} 2$ resolution, the difference to the GRACE-like resolutions is the largest in the medium layer, due to steep basin boundary in this layer, as explained above. Even though there are a few latitudes with poor correlation in the deep layer for the GRACE-like resolutions (e.g., between 25 and $30^{\circ} \mathrm{N}$, and 40 to $50^{\circ} \mathrm{N}$ ), the correlation coefficients are overall higher than in the upper two layers, where most correlation coefficients are below 0.5. Most correlation coefficients with the time series from OBP at the original ECCO2 resolution are significant (Fig. 8 black curve above red dashed $95 \%$ significance level), while significance of the correlation coefficients varies a lot with latitude for GRACE-like resolutions (all other curves). Especially in the deep layer, there are several latitudes where correlation coefficients for mascons with CRI are well above the $95 \%$ significance level, e.g., 20-25, $30-40$, and $55-60^{\circ} \mathrm{N}$. Again, this indicates that the less steep bathymetry in the deep layer is more favorable for GRACElike resolutions. 

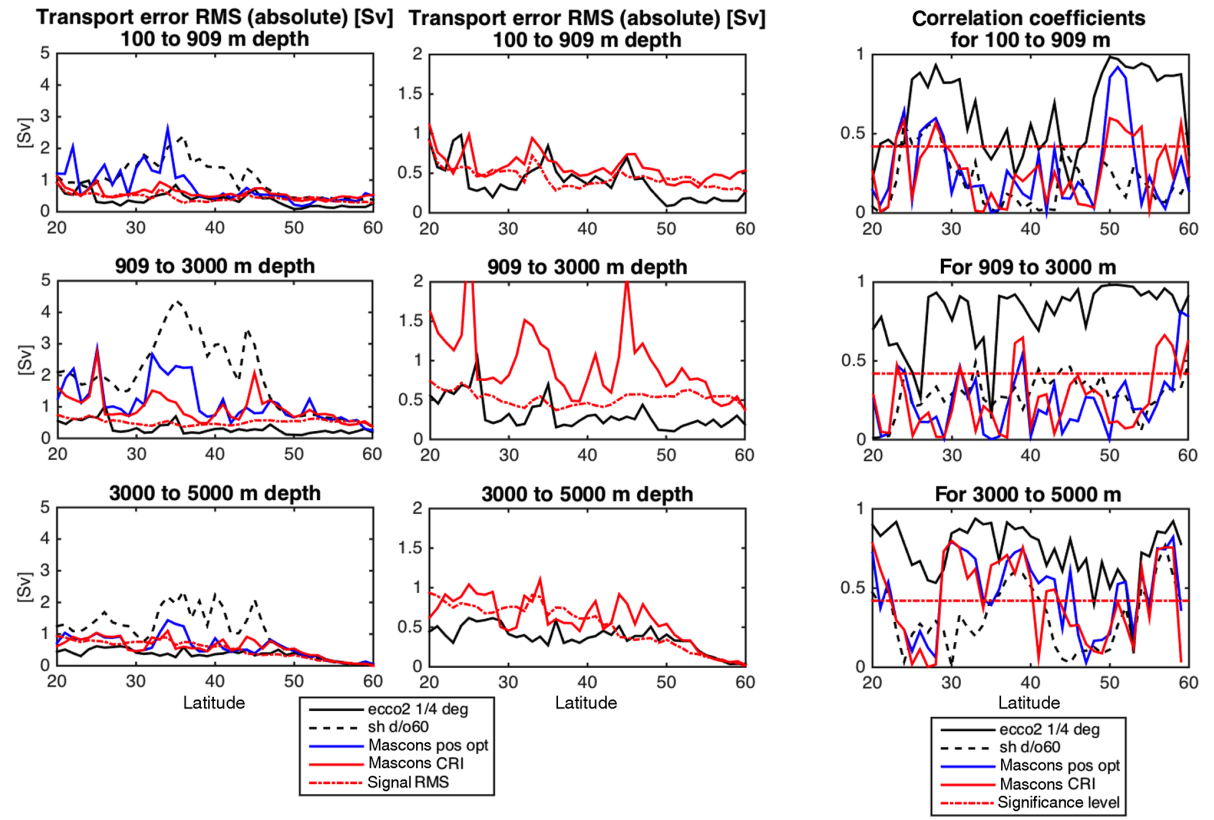

Figure 7. Root mean square error and correlation coefficients for reconstructed net transport in three different depth layers and from different OPB resolutions (native ECCO2 grid vs. GRACE-like resolutions). Left: rms error for the computed time series and rms signal time series (red dashed); center: selection of two cases of rms error and different scales on the plots; right: correlation coefficients of the derived time series versus the model truth. Red dashed line indicates the $95 \%$ significance level.
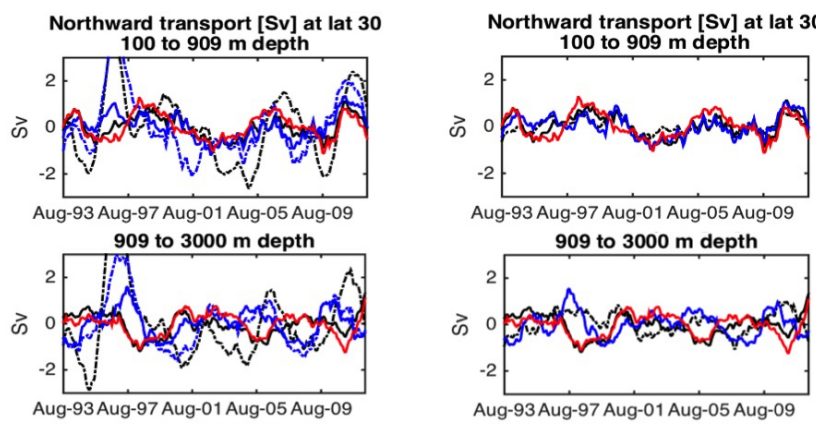

3000 to $5000 \mathrm{~m}$ depth

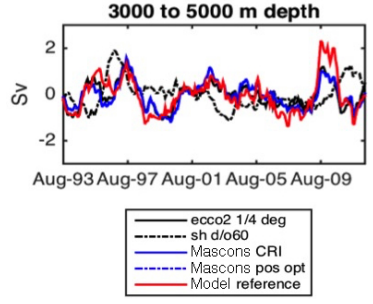

Figure 8. Transport time series anomalies at $30^{\circ} \mathrm{N}$, reconstructed from different OBP data sets versus the model baseline. Left: including land hydrology signal; right: without land hydrology signal.

In conclusion, Fig. 7 shows that the upper and the deep layer transport can be reconstructed from GRACE-like OBP resolutions with rms error of $0.5 \mathrm{~Sv}$ and correlation coefficients of about 0.7 , as long as leakage from land hydrology is accounted and corrected for. The medium layer (909 to $3000 \mathrm{~m}$ depth) is much less suitable for transport reconstruc- tion from GRACE-like OBP resolutions, because the steep bathymetry in this layer cannot be resolved well by GRACE.

Figure 8 shows one example for reconstructed transport time series at $30^{\circ} \mathrm{N}$. The left-hand side of the figure shows the results for OBP time series including continental hydrology, while the right-hand side shows the corresponding time series, but for the OBP signal only, without hydrology. The magnitude of the model reference signal which we are trying to recover is about the same for the upper and the intermediate layer (well below $2 \mathrm{~Sv}$ ), but it reaches and exceeds $2 \mathrm{~Sv}$ in some months for the deep layer. In the upper and intermediate layer, there is a very large signal magnitude in the time series derived from spherical harmonics and position-optimized mascons including land hydrology. This large signal magnitude is caused by leakage of the continental hydrology signal (larger magnitude than OBP signal). It is not present in the solution without hydrology. Also note that leakage affects even the intermediate depth layer at this latitude, i.e., below $909 \mathrm{~m}$ depth. The original ECCO2 grid is not affected by hydrology; therefore the solid black curves are the same in the plots on the right and on the left. Leakage from continental hydrology does not affect the very deep layers; thus, the results on the right and on the left for the deep layer are the same. Without any leakage, reconstruction of the transport signal works well for all different OBP time series for the upper layer. However, this scenario is not very realistic. Even though a good portion of the signal can be recovered, the solution from spherical harmon- 
ics shows the largest discrepancies from the model reference for the scenario without hydrology. From the mascon resolution, the signal can be recovered well in the deep layer; however, there are some discrepancies in the intermediate layer which are due to signal leakage across different depth due to steep bathymetry. In conclusion, first and foremost, continental hydrology has to be taken into account, for example with the CRI filter for the mascons. Second, leakage across steep bathymetry contaminates the transport signal derived from mascon-resolution OBP. Favorable latitudes and depth layers for less steep bathymetry gradients have to be chosen.

Finally, Fig. 9 shows our AMOC reconstruction for $30^{\circ} \mathrm{N}$, derived by summing up the time series for the intermediate and the deep transport layer, i.e., showing the total southward transport (which we assume to be compensating for the entire AMOC northward transport). The model reference time series is matched closely by the time series derived from OBP at the original ECCO2 grid. There are some larger discrepancies between the model reference and the time series derived from mascons (with CRI) (blue curve in Fig. 9). Nevertheless, the model reference can be recovered with an rms error of $0.90 \mathrm{~Sv}$ and a correlation coefficient of 0.63 . While in the deep layer transport (bottom panel, left, in Fig. 8) the time series derived from mascons with CRI and the original ECCO2 grid are very similar (black and blue solid curves), they differ for the intermediate layer, while the black curve (ECCO2 grid) is closer to the model reference. This is what introduces errors in the mascon time series in Fig. 9. While the CRI takes care of continental hydrology leakage, there is leakage across the steep bathymetry at depths between 909 and $3000 \mathrm{~m}$ (compare solid blue curves on the left- and righthand side, intermediate panel in Fig. 8).

\section{Summary and outlook}

Our model studies have shown that, even though signal leakage (from hydrology and across different depths layers) is a challenge at GRACE-like resolutions, the AMOC anomaly time series can be retrieved from GRACE-like OBP observations with errors of $\pm 1 \mathrm{~Sv}$ and below. (This is of similar accuracy as for the full time variable AMOC recovery by RAPID; McCarthy et al., 2015). Chambers and Bonin (2012) reported a mean error of $2 \mathrm{~cm}$ in the coarser spherical harmonic GRACE solutions in the North Atlantic. Such an OBP error would result in an error of about $0.002 \mathrm{~Sv} \mathrm{~m}^{-1}$ in the derived meridional transport. Assuming the northward transport layer spans roughly $1000 \mathrm{~m}$, this leads to an error of about $2 \mathrm{~Sv}$ from spherical harmonics. However, we note that mascon data errors are estimated to be about $30 \%$ smaller than this in the current study region (see Watkins et al., 2015). The AMOC retrieval is rather sensitive to the bathymetry profile, and therefore the quality of the signal recovery is very latitude-dependent (Fig. 7, errors vary with latitude and depth layer from 0.05 to $5 \mathrm{~Sv}$ ). Furthermore, rms error levels are of the same order of magnitude as signal rms

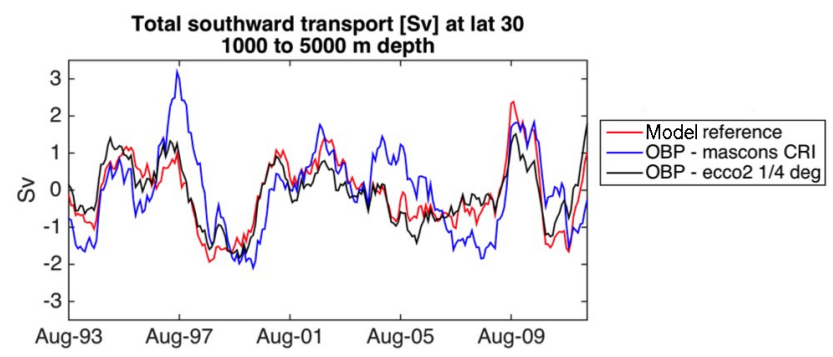

Figure 9. Comparison of AMOC transport anomalies at $30^{\circ} \mathrm{N}$, reconstructed from OBP (blue and black lines) versus model baseline (red line; from velocities, rms $0.92 \mathrm{~Sv}$ ). The rms error (relative to the baseline) for the mascon reconstruction is $0.90 \mathrm{~Sv}$, and for the ECCO 2 grid OBP is $0.43 \mathrm{~Sv}$. The correlation with the baseline transport is $R=0.63$ (mascon grid) and $R=0.88$ (ECCO2 grid OBP).

levels (Fig. 7); they are smaller only for selected depths and latitudes. However, in the deeper layers of the ocean (where the bathymetry gradients are less steep than in shallower layers), OBP measurements at GRACE-like resolutions lead to errors below $1 \mathrm{~Sv}$, while they are up to $3 \mathrm{~Sv}$ for the other two layers (Fig. 7). Thus, the deep layer appears to be the most suitable target to retrieve ocean transports from OBP observations at GRACE-like resolutions. Since the AMOC is not very coherent with latitude and OBP recorder measurements suffer from drift over longer periods of time, satellite gravity measurements (GRACE-like OBP) present a unique data set to monitor AMOC changes over large areas (like the whole North Atlantic Basin) and over extended periods of time (GRACE time series span from 2002 up to today). However, while long-term trends can be accurately recovered by GRACE, the uncertainty of necessary GRACE trend corrections such as Glacial Isostatic Adjustment (A et al., 2013) and continental hydrology leakage (Chambers and Bonin, 2012) makes it challenging to observe a transport-related OBP trend. Our next steps and ongoing work are to move from model simulations to real data and use the OBP integration analysis on JPL5M GRACE mascons to derive real AMOC anomaly time series for all of the Atlantic Ocean from the satellite-based OBP observations.

Acknowledgements. The research described in this paper was carried out at the Jet Propulsion Laboratory, California Institute of Technology, sponsored by the National Aeronautics and Space Administration (NASA), and with support from the NASA Physical Oceanography program.

Copyright 2015 California Institute of Technology. U.S. Government sponsorship acknowledged.

Edited by: A. Sterl 


\section{References}

A, G., Wahr, J., and Zhong, S.: Computations of the viscoelastic response of a 3-D compressible earth to surface loading: An application to glacial isostatic adjustment in Antarctica and Canada, Geophys. J. Int., 192, 557-572, doi:10.1093/gji/ggs030, 2013.

Bingham, R. J. and Hughes, C. W.: Determining North Atlantic meridional transport variability from pressure on the western boundary: A model investigation, J. Geophys. Res., 113, C09008, doi:10.1029/2007JC004679, 2008.

Bingham, R. J. and Hughes, C. W.: Geostrophic dynamics of meridional transport variability in the subpolar North Atlantic, J. Geophys. Res., 114, C12029, doi:10.1029/2009JC005492, 2009a.

Bingham, R. J. and Hughes, C. W.: Signature of the Atlantic meridional overturning circulation in sea level along the east coast of North America, Geophys. Res. Lett., 36, L02603, doi:10.1029/2008GL036215, 2009b.

Bingham, R. J. and Hughes, C. W.: Local diagnostics to estimate density-induced sea level variations over topography and along coastlines, J. Geophys. Res., 117, C01013, doi:10.1029/2011JC007276, 2012.

Chambers, D. P. and Bonin, J. A.: Evaluation of Release-05 GRACE time-variable gravity coefficients over the ocean, Ocean Sci., 8, 859-868, doi:10.5194/os-8-859-2012, 2012.

Elipot, S., Frajka-Williams, E., Hughes, C. W., and Willis, J. K.: The Observed North Atlantic Meridional Overturning Circulation: Its Meridional Coherence and Ocean Bottom Pressure, J. Phys. Oceanogr., 44, 517-537, doi:10.1175/JPO-D-13-026.1, 2013.

Elipot, S., Frajka-Williams, E., Hughes, C. W., and Willis, J. K.: The Observed North Atlantic Meridional Overturning Circulation: Its Meridional Coherence and Ocean Bottom Pressure, J. Phys. Oceanogr., 44, 517-537, doi:10.1175/JPO-D-13-026.1, 2014.

Frajka-Williams, E.: Estimating the Atlantic overturning at $26^{\circ} \mathrm{N}$ using satellite altimetry and cable measurements, Geophys. Res. Lett., 42, 3458-3464, doi:10.1002/2015GL063220, 2015.

Greatbatch, R. J.: A note on the representation of steric sea level in models that conserve volume rather than mass, J. Geophys. Res., 99, 12767-12771, 1994.

IPCC: Climate Change 2014: Impacts, Adaptation, and Vulnerability. Part A: Global and Sectoral Aspects, in: Contribution of Working Group II to the Fifth Assessment Report of the Intergovernmental Panel on Climate Change, edited by: Field, C. B., Barros, V. R., Dokken, D. J., Mach, K. J., Mastrandrea, M. D., Bilir, T. E., Chatterjee, M., Ebi, K. L., Estrada, Y. O., Genova, R. C., Girma, B., Kissel, E. S., Levy, A. N., MacCracken, S., Mastrandrea, P. R., and White, L. L., Cambridge University Press, Cambridge, UK and New York, NY, USA, 1132 pp., 2014.

Kanzow, T., Cunningham, S. A., Rayner, D., Hirschi, J. J.-M., Johns, W. E., Baringer, M. O., Bryden, H. L., Beal, L. M., Meinen, C. S., and Marotzke, J.: Observed Flow Compensation Associated with the MOC at $26.5^{\circ} \mathrm{N}$ in the Atlantic, Science, 317, 938-941, doi:10.1126/science.1141293, 2007.

Kanzow, T., Cunningham, S. a., Johns, W. E., Hirschi, J. J.-M., Marotzke, J., Baringer, M. O., Meinen, C. S., Chidichimo, M. P., Atkinson, C., Beal, L. M., Bryden, H. L., and Collins, J.: Seasonal Variability of the Atlantic Meridional Overturning Circulation at $26.5^{\circ} \mathrm{N}$, J. Climate, 23, 5678-5698, doi:10.1175/2010JCLI3389.1, 2010.

Knight, J. R., Allan, R. J., Folland, C. K., Vellinga, M., and Mann, M. E.: A signature of persistent natural thermohaline circula- tion cycles in observed climate, Geophys. Res. Lett., 32, L20708, doi:10.1029/2005GL024233, 2005.

Landerer, F. W. and Swenson, S. C.: Accuracy of scaled GRACE terrestrial water storage estimates, Water Resour. Res., 48, W04531, doi:10.1029/2011WR011453, 2012.

Manabe, S. and Stouffer, R. J.: The role of thermohaline circulation in climate, Tellus B, 51, 91-109, doi:10.1034/j.16000889.1999.00008.x, 1999.

Marotzke, J., Giering, R., Zhang, K. Q., Stammer, D., Hill, C., and Lee, T.: Construction of the adjoint MIT ocean general circulation model and application to Atlantic heat transport sensitivity, J. Geophys. Res.-Oceans, 104, 29529-29547, doi:10.1029/1999JC900236, 1999.

McCarthy, G., Frajka-Williams, E., Johns, W. E., Baringer, M. O., Meinen, C. S., Bryden, H. L., Rayner, D., Duchez, a., Roberts, C., and Cunningham, S. A.: Observed interannual variability of the Atlantic meridional overturning circulation at $26.5^{\circ} \mathrm{N}$, Geophys. Res. Lett., 39, doi:10.1029/2012GL052933, 2012.

McCarthy, G., Smeed, D., Johns, W., Frajka-Williams, E., Moat, B., Rayner, D., Baringer, M., Meinen, C., Collins, J., and Bryden, H.: Measuring the Atlantic Meridional Overturning Circulation at $26^{\circ} \mathrm{N}$, Prog. Oceanogr., 130, 91-111, doi:10.1016/j.pocean.2014.10.006, 2015.

Menemenlis, D., Campin, J.-M., Heimbach, P., Hill, C., Lee, T., Nguyen, A., Schodlok, M., and Zhang, H.: ECCO2: High Resolution Global Ocean and Sea Ice Data Synthesis, Mercat. Ocean Q. Newsl., p. 13, 2008.

Polster, A., Fabian, M., and Villinger, H.: Effective resolution and drift of paroscientific pressure sensors derived from long-term seafloor measurements, Geochem. Geophy. Geosy., 10, Q08008, doi:10.1029/2009GC002532, 2009.

Rodell, M., Houser, P. R., Jambor, U., Gottschalck, J., Mitchell, K., Meng, C.-J., Arsenault, K., Cosgrove, B., Radakovich, J., Bosilovich, M., Entin, J. K., Walker, J. P., Lohmann, D., and Toll, D.: The Global Land Data Assimilation System, B. Am. Meteorol. Soc., 85, 381-394, doi:10.1175/BAMS-85-3-381, 2004.

Roussenov, V. M., Williams, R. G., Hughes, C. W., and Bingham, R. J.: Boundary wave communication of bottom pressure and overturning changes for the North Atlantic, J. Geophys. Res., 113, C08042, doi:10.1029/2007JC004501, 2008.

Send, U., Lankhorst, M., and Kanzow, T.: Observation of decadal change in the Atlantic meridional overturning circulation using 10 years of continuous transport data, Geophys. Res. Lett., 38, 1-5, doi:10.1029/2011GL049801, 2011.

Srokosz, M., Baringer, M., Bryden, H., Cunningham, S., Delworth, T., Lozier, S., Marotzke, J., and Sutton, R.: Past, present, and future changes in the atlantic meridional overturning circulation, B. Am. Meteorol. Soc., 93, 1663-1676, doi:10.1175/BAMS-D11-00151.1, 2012.

Tapley, B. D., Bettadpur, S., Ries, J. C., Thompson, P. F., and Watkins, M. M.: GRACE Measurements of Mass Variability in the Earth System, Science, 305, 503-505, doi:10.1126/science.1099192, 2004.

Vellinga, M. and Wood, R. A.: Global Climatic Impacts of a Collapse of the Atlantic Thermohaline Circulation, Clim. Change, 54, 251-267, 2002.

Wahr, J., Molenaar, M., and Bryan, F.: Time variability of the Earth's gravity field: Hydrological and oceanic effects and their 
possibel detection using GRACE, J. Geophys. Res., 103, 205229, doi:10.1029/98JB02844, 1998.

Watkins, M. M., Wiese, D. N., Yuan, D.-N., Boening, C., and Landerer, F. W.: Improved methods for observing Earth's time variable mass distribution with GRACE using spherical cap mascons, J. Geophys. Res. Sol. Ea., 120, 1-24, doi:10.1002/2014JB011547, 2015.

Willis, J. K.: Can in situ floats and satellite altimeters detect longterm changes in Atlantic Ocean overturning?, Geophys. Res. Lett., 37, L06602, doi:10.1029/2010GL042372, 2010.
Wunsch, C. and Heimbach, P.: Two decades of the atlantic meridional overturning circulation: Anatomy, variations, extremes, prediction, and overcoming its limitations, J. Climate, 26, 71677186, doi:10.1175/JCLI-D-12-00478.1, 2013.

Zhang, R.: Coherent surface-subsurface fingerprint of the Atlantic meridional overturning circulation, Geophys. Res. Lett., 35, 1-6, doi:10.1029/2008GL035463, 2008. 